\title{
Efforts to improve the understanding of blood circulation concepts through the guided discovery learning model
}

\author{
Mohamad Zakia Mathori \\ SDN Sidaurip 04 Gandrungmangu \\ zmathori@gmail.com
}

\section{Article History}

accepted $14 / 11 / 2020$

approved 21/11/2020

published 26/11/2020

\begin{abstract}
The problem in this research is how the application of the Guided Discovery Learning Model can improve the understanding of science concepts in elementary school students? Purpose To determine the application of the Guided Discovery Learning Model can improve understanding of science concepts in elementary school students. The object of this research is the fifth grade students of SDN Sidaurip 04 Gandrungmangu. The data collection technique was carried out systematically with standard procedures, namely, learning outcome data was taken through tests at the end of each cycle and observation of student participation. The data were analyzed using quantitative and qualitative analyzes of the formative test results. Then, the results of the calculations were consulted with the success criteria, to determine whether they were complete or not. Based on the results of the evaluation test from the first and second cycles, an increase in learning completeness was obtained. In the first cycle achieved learning outcomes with $66.67 \%$ completeness. In the second cycle the completeness of learning outcomes was $88.89 \%$. Based on the findings and results obtained in the study, it can be concluded that, through the Guided Discovery Learning Model, it can improve understanding of the science concept of elementary school students.
\end{abstract}

Keywords: Guided discovery learning, Concept understanding, Learning Outcomes

\begin{abstract}
Abstrak
Permasalahan dalam penelitian ini adalah Bagaimana penerapan Model Guided discovery learning dapat meningkatkan pemahaman konsep IPA pada siswa Sekolah Dasar ? Tujuan Untuk mengetahui penerapan Model Guided discovery learning dapat meningkatkan pemahaman konsep IPA pada siswa sekolah dasar. Objek penelitian ini adalah siswa kelas V SDN Sidaurip 04 Gandrungmangu. Teknik pengumpulan data dilakukan secara sistematis dengan prosedur standar yaitu, data hasil belajar diambil melalui tes setiap akhir siklus dan observasi partisipasi peserta didik. Data dianalisis menggunakan analisis kuantitatif dan kualitatif terhadap perolehan hasil tes formatif kemudian, hasil perhitungan dikonsultasikan dengan kriteria keberhasilan, untuk mengetahui tuntas atau belum tuntas. Berdasarkan hasil tes evaluasi dari siklus pertama, dan kedua diperoleh peningkatan ketuntasan belajar. Pada siklus pertama mencapai hasil belajar dengan ketuntasan $66,67 \%$. Pada siklus kedua ketuntasan hasil belajar sebanyak $88,89 \%$. Berdasarkan temuan dan hasil-hasil yang diperoleh dalam penelitian dapat ditarik kesimpulan bahwa, melalui Model Guided discovery learning dapat meningkatkan pemahaman kosep IPA pada siswa Sekolah Dasar.

Kata kunci: Guided discovery learning, Pemahaman konsep, Hasil Belajar
\end{abstract}

Social, Humanities, and Education Studies (SHEs): Conference Series https://jurnal.uns.ac.id/shes

p-ISSN 2620-9284

e-ISSN 2620-9292 


\section{PENDAHULUAN}

Pendidikan adalah sarana untuk belajar. Belajar adalah proses perubahan tingkah laku yang dipengaruhi oleh adanya pengalaman. Pembentukan tingkah laku ini meliputi perubahan keterampilan, kebiasaan, sikap, pengetahuan, pemahaman, dan apresiasi. Selain itu, belajar adalah proses melihat, mengamati, memahami sesuatu yang dipelajari.

Dengan demikian, belajar merupakan suatu proses usaha yang dilakuakan individu secara sadar untuk memperoleh perubahan tingkah laku tertentu, baik yang dapat diamati secara langsung maupun yang tidak dapat diamati secara langsung sebagai pengalaman (latihan) dalam interaksinyadengan lingkungan (Suprihatiningrum, 2016: 14).

Widiana (2016: 149) pembelajaran IPA di sekolah dasar memiliki peranan penting dalam pembelajaran IPA di jenjang-jenjang berikutnya sebab pengetahuan awal siswa sangat berpengaruh pada minat dan kecenderungan siswa untuk belajar IPA. Siswa pada saat pembelajaran IPA di SD jika minatnya sudah rendah kemungkinan besar untuk jenjang selanjutnya hal yang sama akan terjadi. Mata pelajaran tersebut sangat berkaitan dengan kehidupan sehari hari dan juga termasuk dalam mata pelajaran yang diujikan untuk ujian nasional.

Pendidikan IPA memegang peranan sangat penting dalam kehidupan manusia. Hal ini disebabkan karena kehidupan manusia sangat tergantung dari alam, zat terkandung di alam, dan segala jenis gejala yang terjadi di alam. IPA merupakan rumpun ilmu yang memiliki karakter khusus yaitu mempelajari fenomena alam yang faktual (factual), baik berupa kenyataan (reality) atau kejadian (events) dan hubungan sebab-akibatnya. Cabang ilmu yang termasuk anggota rumpun IPA saat ini antara lain Biologi, Fisika, Astronomi/Astrofisika, dan Geologi (Asih dan Sulistyowati, 2014: 22).

Dalam pelajaran IPA Biologi peredaran darah pada manusia adalah sistem yang dapat mengedarkan darah dari jantung hingga ke seluruh tubuh dan akan kembali lagi ke jantung yang meliputi komponen-komponen dalam sistem peredaran darah pada manusia. Darah komponen terpenting karena darah berfungsi sebagai pembawa nutrisi dan oksigen keseluruh tubuh, ada tiga macam sel darah yaitu (Sel darah merah, Keping darah, sel darah putih).

Jantung merupakan organ vital ditubuh manusia yang bertugas sebagai pemompa darah ke seluruh tubuh, melalui serambi kiri dan bilik kiri jantung berisi darah bersih yang kaya akan oksigen, sedangkan bilik dan serambi kanan berisi darah kotor. Pembuluh darah berfungsi mengalirkan darah dari jantung ke seluruh tubuh, dan dari seluruh tubuh kembali ke jantung pembuluh dibagi menjadi tiga jenis yaitu (Arteri, Venula, Vena, dan Kapilar) dan paru-paru berfungsi menyuplai oksigen ke dalam tubuh.

Dengan diterapkannya model guided discovery learning diharapkan siswa lebih memahami IPA materi peredaran darah pada manusia, siswa mampu mendapatkan hasil belajar lebih baik dari sebelumnya. Model penemuan (discovery) merupakan pembelajaran yang lebih menekankan pada pengalaman langsung. Pembelajaran dengan model penemuan lebih mengutamakan proses dari pada hasil. Model guided discovery learning adalah suatu pendekatan mengajar di mana guru memberi siswa contoh-contoh topik spesifik dan memandu siswa untuk memahami topik tersebut (Eggen dan Kaunchak, 2012: 177).

Model guided discovery learning sangat tepat diterapkan dalam pembelajaran IPA khususnya materi peredaran darah pada manusia. Siswa akan terlibat secara langsung dalam proses pembelajaran karena meraka akan menemukan sendiri apa yang mereka pelajari dengan bimbingan guru dengan cara mereka menemukan sendiri materinya itu berarti mereka lebih paham terhadap materi tersebut dan tentunya pembelajarannya akan lebih bermakna. 
Berdasarkan latar belakang tersebut, penulis tertarik untuk melakukan Penelitian Tindakan Kelas (PTK) dengan judul "UPAYA PENINGKATAN PEMAHAMAN KONSEP PEREDARAN DARAH MELALUI MODEL GUIDED DISCOVERY LEARNING PADA SISWA KELAS V SDN SIDAURIP 04 TAHUN PELAJARAN 2020/2021"

\section{METODE}

Objek penelitian kali ini adalah siswa kelas V SDN Sidaurip 04 Gandrungmangu. Metode yang digunakan dalam penelitian adalah metode kuantitatif untuk menentukan data harus menggunakan observasi Proses analisis data menggunakan statistik. data tersebut dapat diolah menggunakan tabel dan grafik .Observasi yang dilakukan selama proses pembelajaran menggunakan observasi terfokus yang secara khusus ditujukan untuk mengamati aspek tertentu dari pembelajaran. Aspek yang akan diamati adalah partisipasi peserta didik, respon peserta didik dalam menjawab pertanyaan dan keaktifan peserta didik menggunakan alat observasi terstruktur yaitu menggunakan instrumen observasi siap pakai, sehingga pengamat tinggal membubuhkan tanda cek $(\sqrt{ })$ pada lembar yang tersedia setiap pengamatan ada kemunculan yang sesuai dengan fokus yang telah ditetapkan. Selain itu peneliti juga membagikan angket kepada peserta didik untuk dijadikan data selama proses pembelajaran.Observasi tentang prestasi belajar berupa nilai hasil evaluasi yang dilakukan pada setiap akhir siklus. Sedangkan alat tes untuk mengukur hasil belajar adalah soal tertulis pada lembar evaluasi.

\section{HASIL DAN PEMBAHASAN}

Penelitian Peningkatan Pemahaman Konsep IPA melalui Guided model Discovery Learning dilaksanakan dalam dua siklus yaitu siklus I dan Siklus II. Dalam kaitannya dengan pendidikan, Hamalik (dalam Takdir, 2012:29) menyatakan bahwa discovery adalah proses pembelajaran yang menitikberatkan pada mental intelektual pada anak didik dalam memecahkan berbagai persoalan yang dihadapi, sehingga menemukan suatu konsep yang dapat diterapkan di lapangan

Menurut Syah (2004:244) dalam mengaplikasikan Discovery Learning di kelas, ada beberapa prosedur yang harus dilaksanakan dalam kegiatan belajar mengajar secara umum sebagai berikut: Stimulation (Stimulasi/Pemberian Rangsangan),problem Statement (Pernyataan/Identifikasi Masalah), Data Collection (Pengumpulan Data), Data Processing (Pengolahan Data), Verification (Pembuktian), Generalization (Menarik Kesimpulan/Generalisasi),

Guided discovery learning terdiri dari tiga suku kata, yaitu yang pertama terdiri dari kata "guided" yang artinya terbimbing, yang kedua "discovery" yang artinya penemuan, dan yang terakhir yaitu "learning" yang artinya pembelajaran. Jadi jika digabungkan guided discovery learning artinya pembelajaran penemuan terbimbing.Menurut Eggen dan Kaunchak (2012:177) modelguided discovery learning adalah suatu pendekatan mengajar di mana guru memberi siswa contoh-contoh topik spesifik dan memandu siswa untuk memahami topik tersebut.

Proses pembelajaran menggunakan model Guided discovery learning. Dari hasil pembelajaran siklus 1, peneliti sudah melakukan kegiatan pembelajaran yang baik sehingga dari 9 siswa yang mencapai tuntas pemahaman konsepnya ada 6 siswa sehingga prosentasenya mencapai $66,67 \%$, namun pemahaman konsep siswa belum tercapai yakni peserta didik yang mencapai 33,33\%.

Perbaikan pembelajaran dilakukan peneliti pada siklus kedua dengan menambah media video pembelajaran tentang peredaran darah pada manusia. Hal ini ternyata dapat meningkatkan pemahaman konsep siswa. Siswa yang mencapai nilai tuntas mencapai 88,89 \% mengalami peningkatan $22 \%$ dari siklus pertama. Partisipasi siswa 
dalam belajar IPa pada siklus I yaitu 32 point meningkat menjadi 33 point pada siklus II. Ditandai dengan adanya dua kemunculan kriteria partisipasi peserta didik. Partisipasi peserta didik pada proses pembelajaran. Untuk lebih jelasnya dapat pada tabel dan grafik berikut ini:

Tabel 1 Data peneliaan model pembelajaran discovery learning berbantuan media audio visual

\begin{tabular}{cllll}
\hline \multicolumn{1}{ll}{ No } & Aspek & Siklu & Siklus & Ket \\
\hline 1 & Hasil Belajar & 66,67 & 88,89 & \\
\hline 2 & Partisipasi peserta didik & 66,67 & 68,75 & \\
\hline 3 & Kegiatan guru & $75 \%$ & $80 \%$ & \\
\hline
\end{tabular}

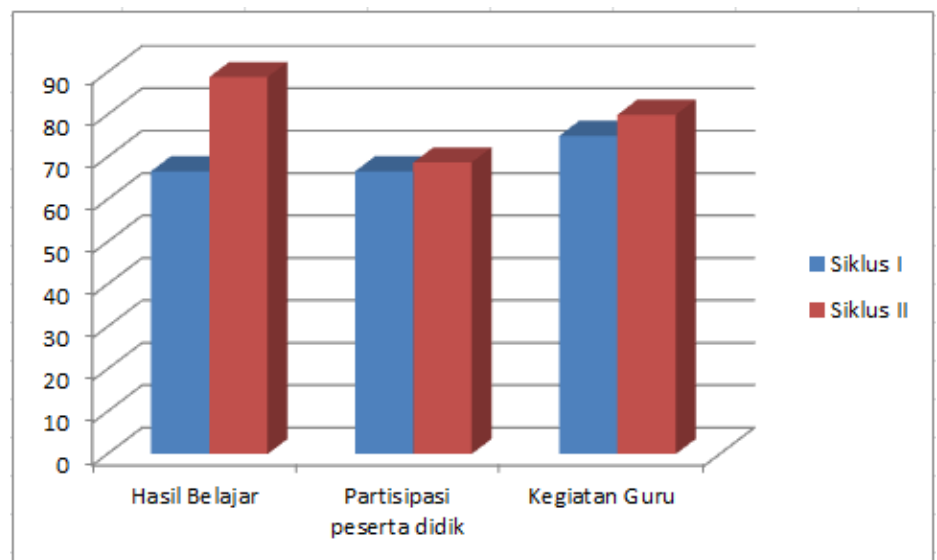

Gambar 1 Data peneliaan model pembelajaran Guided discovery Learning

\section{SIMPULAN}

Berdasarkan hasil temuan dan upaya perbaikan pembelajaran dapat disimpulkan hal-hal sebagai berikut:

1. Kemampuan siswa kelas V SDN Sidaurip 04 Gandrungmangu dalam pemahaman konsep IPA melalui model Guided discovery learning dapat ditingkatkan setelah melalui upaya perbaikan dalam dua siklus dengan tingkat ketuntasan sebesar $88,89 \%$.

2. Pada kegiatan pembelajaran dengan aplikasi google meet, pengkondisian siswa harus tepat dan makasimal agar suara menjadi jelas.

3. Pemberian contoh pada kegiatan pembelajaran memberi kontribusi yang sangat baik terhadap hasil pembelajaran. Pengintegrasian teknologi berupa media vidio terbukti efektif dan sangat membantu siswa dalam memahami materi.

Berdasarkan kesimpulan di atas, berikut ini dikemukakan beberapa rekomendasi yang perlu diperhatikan guru dalam upaya meningkatkan hasil pembelajaran.

1) Pada kegiatan pembelajaran bagian pendahuluan melalui goole meeti, guru harus sudah betul-betul dapat mengkodisikan siswa agar suara dapat terdengar jelas

2) Untuk membantu siswa dalam memahami materi pelajaran secara lebih jelas sebaiknya guru memberi contoh secukupnya dan menggunakan media audio visual.

3) Metode Guided discovery learning direkomendasikan untuk digunakan dalam pembelajaran IPA.

\section{DAFTAR PUSTAKA}

Ahmadi, Abu dan Supatmo. (2000). Ilmu Alamiah Dasar. Cetakan Kedua. Jakarta: PT Rineka Cipta. 
Arikunto, Suharimi, dkk. (2007). Penelitian Tindakan Kelas. Cetakan Keempat. Jakarta: PT Bumi Aksara.

Asih, Sullistyowati. (2014). Metodologi pembelajaran IPA. Jakarta: PT Bumi Aksara.

Eggen, Paul Don Kouchak. (2012). Strategi dan Model Pembelajaran. Jakarta: PT Indeks.

Kementerian Pendidikan dan Kebudayaan. (2017). Tematik Terpadu Kurikulum 2013. Untuk SD/MI Kelas V. Jakarta: Kemendikbud

Kusumah, Wijaya dan Dwitagama. (2010). Penelitian Tindakan Kelas. Edisi Kedua. Jakarta: PT Indeks.

Susanto, Ahmad. (2013). Teori Belajar dan Pembelajaran di Sekolah Dasar. Cetakan Pertama. Jakarta: Kencana Prenada Media Grup.

Suprihatiningrum, Jamil. (2016). Strategi Pembelajaran. Cetakan Ketiga. Yogyakarta: AR-RUZZ Media

Suyadi. (2013). Strategi Pembelajaran Pendidikan Karakter. Bandung: PT Remaja Rosadakarya.

Suwartiningsih. (2015). Penerapan Model Guided Discovery Learning untuk Meningkatkan Hasil Belajar Siswa Tentang Materi Gaya Di Kelas Iv Sekolah Dasar Negeri Licin Kecamatan Cimalaka Kabupaten Sumedang. Skripsi. Sumedang: Universitas Pendidikan Indonesia.

Wisudawati, Asih dan Eka Sulistyowato. (2014). Metodologi Pembelajaran IPA.Cetakan Pertama. Jakarta: Bumi Aksara.

Widiana, Wayan I. (2016). Pengembangan Asesmen Proyek dalam Pembelajaran IPA di Sekolah Dasar. Jurnal Pendidikan Indonesia, 5(2). Bali: Undiksha 